\title{
Separation of divalent metal ions using Pandanus Amaryllifolius Roxb (Pandanus) leaves: desorption study
}

\author{
M. Z. Abdullah \& K. P. Loo \\ Chemical Engineering Programme, Universiti Teknologi Petronas, \\ Perak, Malaysia
}

\begin{abstract}
Desorption by dead biomass has been studied on Pandanus Amaryllifolius Roxb (Pandanus leaves) by conducting batch experiments. The recovery of heavy metals such as lead and copper ions from biomass was examined using a variety of desorbing chemicals. This study aims to discover the best chemical which is able to leach the metal effectively with highest desorbing capacity. The results showed that $\mathrm{HCl}$ at $\mathrm{pH} 2$ and $3.0 \mathrm{mM}$ EDTA at $\mathrm{pH} 4.58$ were effective in desorbing the copper and lead ions from the biomass. The recovery of copper is very feasible since over $90 \%$ of copper was removed from the biomass. The percentage of lead recovery is about $70 \%$. In contrast, $\mathrm{Na}_{2} \mathrm{CO}_{3}$ and $\mathrm{NaOH}$ are not effective in desorbing both of the metals. The results indicated that low $\mathrm{pH}$ is preferable for desorbing the metal ions. The binding ability of $\mathrm{HCl}$ is explained using ion-exchanging principle. More concentrated protons are able to replace those ions thus regenerating the biomass. EDTA is functioning as polydentate ligands, which appear to grasp the metal between the six donor atoms. It was suggested that recovery of metal ions is mainly due to the strength of bonding between the fraction of functional group of biomass and metal ions. Recovery of the deposited metals can be accomplished because they can be released from the saturated biomass in a concentrated wash solution, which also regenerates the biomass for reuse. Desorbing chemicals such as $\mathrm{HCl}$ and EDTA have proved successful for desorbing the metal ions. Thus, biosorption of heavy metals by biomass will be emerged as one of the alternative technology in removing the heavy metals.
\end{abstract}

Keywords: Pandanus Amaryllifolius Roxb, copper, lead, biosorption, adsorption, desorption. 


\section{Introduction}

The current technologies for heavy metals removal from industrial effluents appear to be inadequate and expensive. Thus, research on biomass including bacteria, plant, algae, fungi and yeast are found to be capable in adsorbing heavy metals. Biosorption mechanisms involved in the process might include ion exchange, complexation, chelation, adsorption and precipitation [1]. The active sites present on cell wall can be very different according to the nature of the biosorbent: carboxylic, phosphate, sulphate, amino, amide, and hydroxyl groups are most commonly found [2].

Interest in using plants for environmental remediation is increasing due to their nature ability in capturing the heavy metals. Moreover, plant species that have been found growing on heavy metal-contaminated soils have a tolerance to the toxic effect of heavy metals. It might due to the evolution of chemical functional groups that reduce the toxic effect of heavy metals.

According to Guangyu and Viraraghaven, both living and dead biomass possess biosorption capacity. The performance of living biomass in binding metal ions depends not only on the nutrient and environmental status, but also cell age. Living cells are subjected to toxic effect of certain level of heavy metals, thus resulting in cell death. Non-viable and dead biomass is preferred in removing metal ions as they can also be regenerated and reused easily [3].

Recovery of the deposited metals can be accomplished because they can be released from the saturated biomass in a concentrated wash solution, which also regenerates the biomass for reuse. Several desorbing chemical such as acid and chelating agent have been proved successfully in desorbing the metal ions [4]. Thus, biosorption of heavy metal by biomass has emerged as one of the alternative technology in removing the heavy metals.

Different affinities of metal ions for biosorbent result in certain degree of metal selectivity on the uptake. Likewise, selectivity may be achieved upon the elution-desorption operation, which may serve as another means of eventually separating metals from one another if possible.

Batch experimentation was used to determine the desorption capacity using $0.1 \mathrm{M} \mathrm{HCl}$ on the metal bounded to African alfalfa shoot [5]. The saturated biomass was exposed to $2 \mathrm{ml}$ of $0.1 \mathrm{M} \mathrm{HCl}$, equilibrated by rocking for 5 minutes, and then centrifuged. Supernatants were collected for analysis using Atomic Absorption Spectrometer (AAS).

From the $\mathrm{pH}$ profile studies of heavy metal binding by African alfalfa shoot; heavy metal uptake was low at low pHs. It is then suggested that the protons would displace the adsorbed heavy metal ions by lowering the $\mathrm{pH}$. It was reported that lead and cadmium achieved the most percentage of recovery (more than $99 \%$ ) followed by zinc. By using acid at this low strength, the biomaterial is not destroyed and it can be reused. Alfalfa biomass was also performed in immobilized column experiment. The results showed that almost $90 \%$ of lead and zinc was removed from the column. For cadmium, recovery was almost $70 \%$. No chromium was recovered. 
The batch and continuous experiment above has indicated that the metal ion with positive two charge have good recoveries. It might due to the metal ion being easier to be displaced by proton ion. The chromium, which has +3 charge, might have a stronger bond with the binding sites of the biomass and it may require a stronger acid concentration or other stripping agent to remove the metal ions.

Adsorption and desorption characteristic of biosorption process consists of biomass of marine algae Sargassum baccularia, cadmium ions and desorbing agents hydrochloric acid $(\mathrm{HCl})$ and ethylenediaminetetraacetic (EDTA) were investigated using a batch reactor system [6]. It was found out that both desorbing agents are capable of stripping the cadmium. $\mathrm{HCl}$ at $\mathrm{pH} 2$ could adsorb more than $80 \%$ of cadmium. Almost complete recovery of cadmium was achieved by using $3.2 \mathrm{mM}$ EDTA solution. However, $\mathrm{HCl}$ was found to reduce cadmium uptake capacity by $56 \%$ while the reduction of EDTA was nearly $40 \%$ over the five adsorption-desorption cycles. The loss of biomass using $\mathrm{HCl}$ is $30 \%$ as the EDTA caused a biomass loss of $16 \%$. The results showed that EDTA is a better desorbing agent than $\mathrm{HCl}$.

A study on the packed bed sorption of copper using spent animal bones stated the use of various concentration of $\mathrm{H}_{2} \mathrm{SO}_{4}$ as desorbing chemical. A solution of $50 \mathrm{mM}$ was found out to be suitable for this process and the efficiency of bonespacked column did not change significantly after four sorption and desorption cycles [7].

Studies were conducted to investigate the removal and recovery of copper (II) ions from aqueous solutions by bacteria Micrococcus.sp. Sodium polyphosphate $(0.1 \mathrm{M})$ and nitric acid $(0.05 \mathrm{M})$ were the most efficient desorption media, recovering more than $90 \%$ of initial copper adsorbed, while the distilled, deionized water control demonstrated no copper desorption [8].

Reutilization of non-viable biomass of the cyanobacterium Phormidium laminosm for metal biosorption was studied [9]. They reported that the biosorbed heavy metal could be desorbed by washing the biomass with diluted acids but not with $\mathrm{NaOH}, \mathrm{NaCl}, \mathrm{CaCl}_{2}$ or ultrapure water. Desorption of biosorbed metal with $0.1 \mathrm{M} \mathrm{HCl}$ allow the reuse of biosorbent for at least five biosorption and desorption cycles without decreasing its biosorption capability.

After the biosorption of toxic heavy metal from a large volume of low concentration aqueous waste, the heavy metal could be eluted from the saturated biomass by desorption or an elution process. Aldor et al investigated equilibrium cadmium desorption from protonated Sargassum by various elutants. It was established that that the mineral acids, particularly $0.1 \mathrm{M} \mathrm{HCl} \mathrm{or} \mathrm{H}_{2} \mathrm{SO}_{4}$ are efficient in metal elution. The biomass damage was limited during the acid wash.

This biosorption study will focus on desorption of divalent metal ions i.e. $\mathrm{Pb}^{2+}$ and $\mathrm{Cu}^{2+}$ from Pandanus Amaryllifolius Roxb (Pandanus) leaves using various desorbing chemicals. Recovery of the deposited metals is accomplished by using the suitable desorbing chemical for reuse of biomass. The possibility of regeneration of loaded biosorbent is crucial in keeping the process cost down and to opening the possibility of recovering the metal extracted from the liquid phase. 


\section{Methodology}

\subsection{Biomass preparation}

The biomass of Pandanus Amaryllifoliusm Roxb (pandanus leaves) was collected at Bota Kanan area in the state of Perak, Malaysia. The biomass was washed thoroughly with distilled water, dried in the oven at $60^{\circ} \mathrm{C}$ for 48 hours and ground using the laboratory grinder for 3 minutes until fine particles were achieved. It was then sieved into particle size ranges of $600 \mu \mathrm{m}$ and $1.18 \mathrm{~mm}$ which were used throughout the experiments.

\subsection{Biosorption experiment}

$2.0 \mathrm{~g}$ biomass was added into $50 \mathrm{ml}, 40$-ppm metal ion solution, containing either $\mathrm{Pb}$ (II) or $\mathrm{Cu}$ (II) salt in different Erlenmeyer flasks. The solution was left to mix on a rotary shaker at $125 \mathrm{rpm}$ for 24 hours to achieve equilibrium and then sieved to separate the filtrate and the biomass. The metal ion concentrations were analysed using the atomic absorption spectrophotometer (AAS) while the biomass were subjected for the desorption experiments.

\subsection{Desorption experiment}

The biomass that were previously separated were added into four different Erlenmeyer flasks containing $25.0 \mathrm{ml}$ of various desorbing solutions i.e. $0.1 \mathrm{M} \mathrm{HCl}, 0.1 \mathrm{M} \mathrm{NaOH}, 0.1 \mathrm{M} \mathrm{Na}_{2} \mathrm{CO}_{3}$ and $3.0 \mathrm{mM}$ EDTA, respectively. The mixture was left to mix on a rotary shaker at $125 \mathrm{rpm}$ for 24 hours to achieve equilibrium. The mixtures were then filtered and the filtrates were analysed using the AAS.

\section{Results and discussion}

\subsection{Biosorption experiment}

The results from adsorption experiment showed that the adsorption of the copper and lead ions are feasible using pandanus leaves.

Figure 1 shows the heavy metal ion uptake by Pandanus Amaryllifolius Roxb while Figure 2 indicates the percentage removal of heavy metal ion by the biomass. The results denote that higher lead adsorption is corresponding to the stronger affinity of lead towards pandanus leaves in a metal ion solution which follow the trend of $\mathrm{Pb}^{2+}>\mathrm{Cu}^{2+}$.

The higher adsorption affinity of lead agrees with the selectivity of the biomass. Sadowski also observes this phenomenon in the uptake of lead and copper by microorganism Nocardia Sp. [10]. The author stated the adsorption of $\mathrm{Pb}^{2+}$ and $\mathrm{Cu}^{2+}$ are mainly due to its electrostatic attraction. The electronegativity of an atom in a molecule is related to its ionization energy and electron affinity. An atom, which has a very negative electrons affinity and high ionization energy will both attract electrons from other atoms and resists having its electron 
attracted away. Therefore, higher electronegativity of metal ion is preferred by biomass.

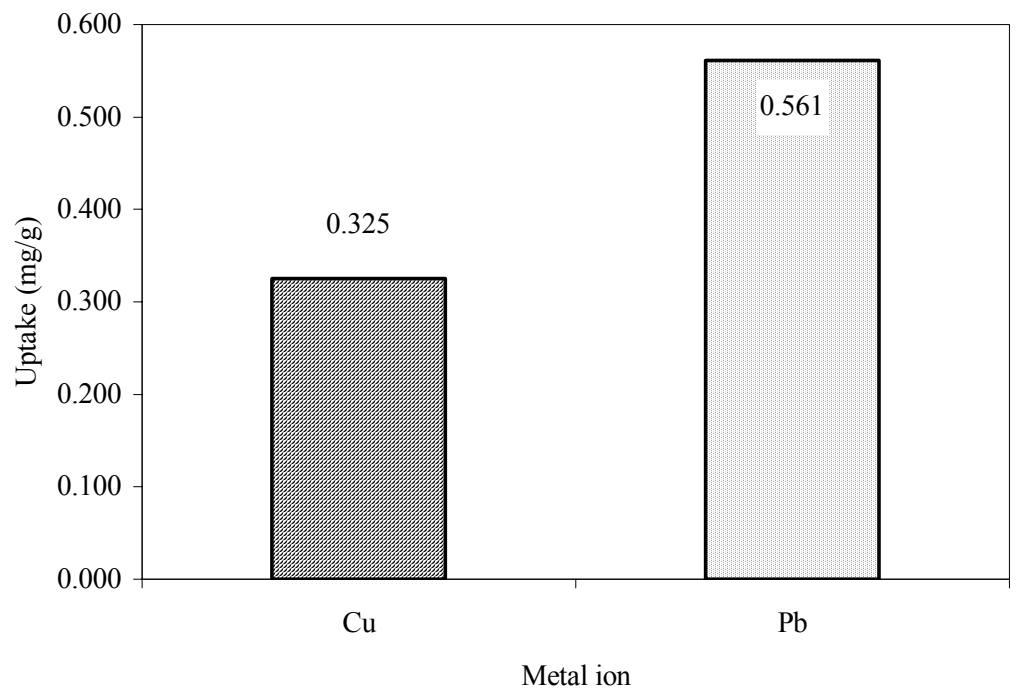

Figure 1: Heavy metal ion uptake by Pandanus amaryllifolius Roxb.

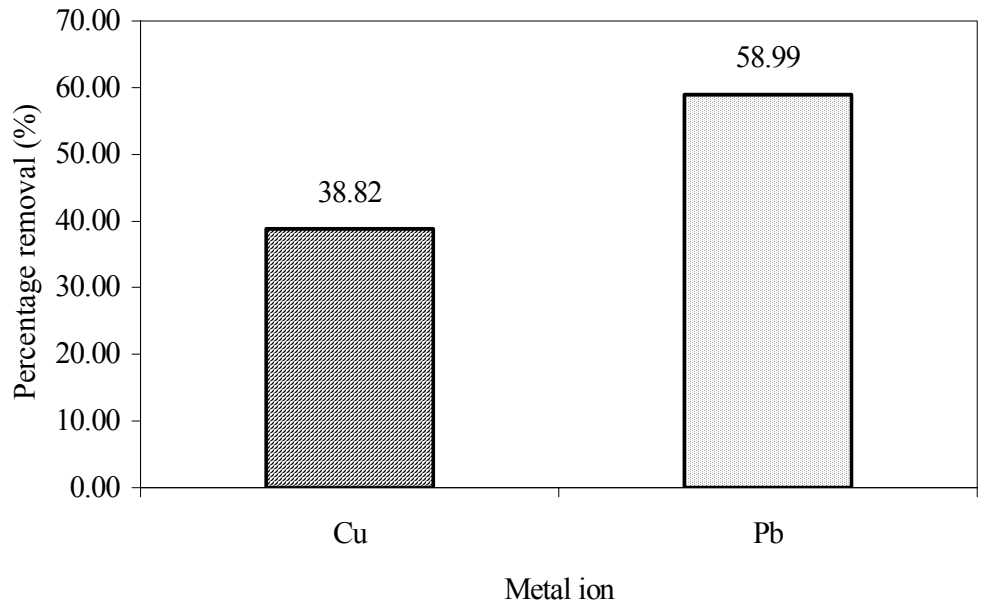

Figure 2: Percentage of heavy metal ion removal by Pandanus Amaryllifolius Roxb.

By ionic radius comparison, lead ion, which has a smaller hydrated diameter possess the higher electronegativity. It has greater tendency to accept electron and share the electron with the weekly acidic cationic biomass, which is an electron donor. 


\subsection{Desorption experiment}

Screening for the effective solution to regenerate saturated pandanus leaves is the main objective of the study. Figure 3 shows adsorbed metal ions could be removed by lowering the $\mathrm{pH}$. $\mathrm{HCl}$ at $\mathrm{pH} 2$ and $3.0 \mathrm{mM}$ EDTA at $\mathrm{pH} 4.58$ were effective in adsorbing the copper ions from the biomass. It was found that recovery of copper ion is very feasible using $\mathrm{HCl}$ since complete removal is observed. EDTA could also desorbs more than $90 \%$ of copper ions initially loaded onto the biomass. The percentage of lead ion recovery using both chemicals is about $74 \%$ and $64 \%$ using $\mathrm{HCl}$ and EDTA respectively, which is expected lower compared to copper removal due to the greater bond experienced between the biomass and metal ion.

Table 1: $\quad \mathrm{pH}$ of desorbing solution.

\begin{tabular}{|c|c|}
\hline Desorbing solution & $\mathrm{pH}$ \\
\hline $0.1 \mathrm{M} \mathrm{HCl}$ & 2.00 \\
\hline $3.0 \mathrm{mM} \mathrm{EDTA}$ & 4.58 \\
\hline $0.1 \mathrm{M} \mathrm{NaOH}$ & 11.20 \\
\hline $0.1 \mathrm{M} \mathrm{Na}_{2} \mathrm{CO}_{3}$ & 12.07 \\
\hline
\end{tabular}

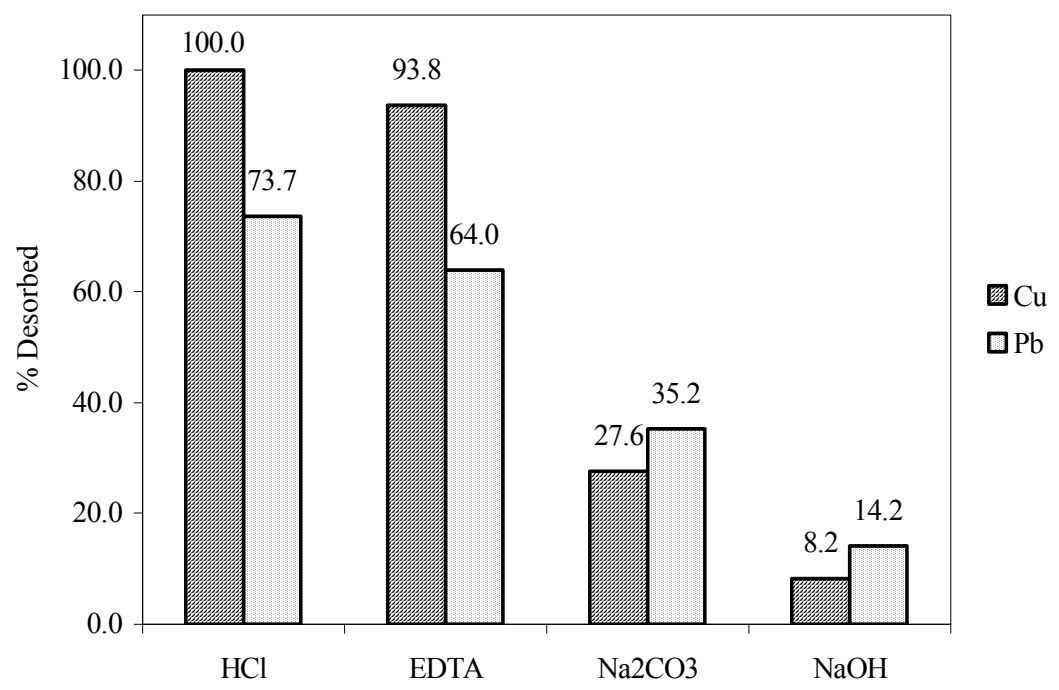

Desorbing chemical

Figure 3: Percentage metal ions being desorbed after contact with desorbing chemicals.

On the contrary, $\mathrm{Na}_{2} \mathrm{CO}_{3}$ and $\mathrm{NaOH}$ are not effective in desorbing copper and lead ions as indicated in Figure 3. The recovery of copper ion is as low as $8 \%$ and $27 \%$ using $\mathrm{Na}_{2} \mathrm{CO}_{3}$ and $\mathrm{NaOH}$, respectively. The low percentage of lead ion recovery also showed that high $\mathrm{pH}$ of chemical is not suitable in desorbing the 
metal ions. Basic solution like $\mathrm{NaOH}$ and $\mathrm{Na}_{2} \mathrm{CO}_{3}$ is widely used to pretreatment biomass to increase the adsorption capability, as they are able to remove surface impurities and expose the available binding sites. However, the pre-treatment using alkali resulted a great loss of biomass [3]. From the observation, the filtrate of copper and lead after desorption were green in colour. It was suggested biomass might be washed out during the desorption process.

The binding of metal ions is an ion exchange reaction where the metal ions are reversibly removed from solution and transfer to the biomass. Ion exchange reversible reaction is given as eqn (1).

$$
(\mathrm{B}-\mathrm{H})+\mathrm{Cu}^{2+} \rightleftharpoons(\mathrm{Cu}-\mathrm{B})+\mathrm{H}^{+}
$$

where B is the functional group of the biomass.

For a weakly acidic cationic exchanger, the adsorption of divalent metals occurred according to eqn (2).

$$
2 \mathrm{RCOOH}+\mathrm{Cu}^{2+} \rightleftharpoons \mathrm{RCOO}_{2} \mathrm{Cu}+2 \mathrm{H}^{+}
$$

where $\mathrm{RCOOH}$ is a resin.

The biomass can be considered as weakly acidic cationic exchanger. The resin is compared with the organic components of pandanus leaves which is consists of carbon and hydrogen compound. Studies found that organic constituents of 2-acetyl-1-pyrroline and ethyl formiate are found in Pandanus leaves [11].

Regeneration of biomass is typically conducted by adding a regenerating solution. Since the reaction is reversible, the more concentrated $\mathrm{H}^{+}$are able to replace those ions thus regenerating the biomass. The reversible reactions associated with ion exchanging can be reverted to left with consequent release of $\mathrm{Cu}^{2+}$ ions if strong acid is mixed with biomass.

$\mathrm{HCl}$ is among the strong acids that act as proton donor, which would displace the adsorbed metal ions. In an aqueous solution of $\mathrm{HCl}$, this acid consists entirely of $\mathrm{H}_{3} \mathrm{O}^{+}$and $\mathrm{Cl}^{-}$ions based on the dissociation in eqn (3).

$$
\mathrm{HCl}(\mathrm{aq})+\mathrm{H}_{2} \mathrm{O}(\mathrm{l}) \rightarrow \mathrm{H}_{3} \mathrm{O}^{+}(\mathrm{aq})+\mathrm{Cl}^{-}(\mathrm{aq})
$$

Therefore, $0.1 \mathrm{M} \mathrm{HCl}$, which is complete, ionized, was proven to be effective in desorbing chemical for copper and lead.

Other concentrated solutions other than acids can be used as regenerating solution. From Figure 3, EDTA is also capable in desorbing the metals. EDTA is a chelating agent that has two or more donor atoms that can simultaneously coordinate to a metal ion. EDTA is functioning as polydentate ligands, which appear to grasp the metal between the six donor atoms. The EDTA has two nitrogen atoms that have unshared pairs of electrons. These six donor atoms are located far apart that the ligand can wrap around a metal ion with the two nitrogen atoms simultaneously complexing to the metal in adjacent positions.

The $[\text { EDTA }]^{4-}$ ion contains one EDTA ligand in the octahedral coordination sphere of $\mathrm{Cu}^{2+}$. Due to metal ions (particularly transition-metal ions) have empty 
valence orbitals, the ions act as Lewis acids (electron pair acceptors). The ligand, which has unshared pairs of electrons, is functioning as Lewis base (electron-pair donors). Thus, metal ion and ligand is bonded as the result of their sharing a pair of electrons that was initially on the ligand.

In general, chelating agents form more stable complexes than do monodentate ligands such as $\mathrm{NH}_{3}$ and $\mathrm{Cl}^{-}$. The formation for [CuEDTA] can be represented in eqn (4).

$$
\left[\mathrm{Cu}\left(\mathrm{H}_{2} \mathrm{O}\right)_{6}\right]^{2+}(\mathrm{aq})+\left[\mathrm{EDTA}^{4-}(\mathrm{aq}) \leftrightarrow[\mathrm{CuEDTA}]^{-}(\mathrm{aq})+6 \mathrm{H}_{2} \mathrm{O}(\mathrm{l})\right.
$$

Although lead being adsorbed the most, the metal recovery using $\mathrm{HCl}$ and EDTA is lower than copper. This result showed that higher uptake of ions is not necessary followed by higher desorption. Biomass in general consists of a large number of functional groups or ligands that may interact with metal ions through variety of mechanism. Fraction of these ligands present on a particular biomass might have stronger bond with particular metal ion.

Hashim et al. stated the strength of bonding between metal ion and biomass can be determined using Langmuir model. The dissociation constant in the denominator of the model is able to indicate the strength of bonding [12]. In this study, lead ion proved to possess greater bond with the functional group of the biomass which is reflected in the higher amount of adsorption. Thus, desorbing chemical might experience intricacy to overcome the bonding and desorbs the metal ions from the biomass. However, lead ions demonstrate higher recovery in acidic medium, as $\mathrm{HCl}$ and EDTA are able to overcome the bonding, compared to in basic medium.

In ion exchange point of view, this phenomenon showed that for the same concentration of different ions, the relative preference of the biomass depends primarily on ionic size. Among ions having the same charge, the ions having the smallest hydrated diameter (largest unhydrated diameter tends to have smaller hydrated diameter) are preferred by the biomass. Typical order of ion exchange preference by the biomass is as follow:

$$
\mathrm{Pb}^{2+}>\mathrm{Hg}^{+}>\mathrm{Ca}^{2+}>\mathrm{Ni}^{2+}>\mathrm{Cd}^{2+}>\mathrm{Cu}^{2+}>\mathrm{Zn}^{+}>\mathrm{Fe}^{2+}>\mathrm{Mg}^{2+}>\mathrm{Mn}^{2+}
$$

\section{Conclusion}

The experimental results has shown that the recovery of heavy metal divalent ions is very feasible using $\mathrm{HCl}$ and EDTA as more than $90 \%$ of copper and $60 \%$ of lead was removed. This suggested that lower $\mathrm{pH}$ is favour in desorbing the metal ions. The protons in $\mathrm{HCl}$ would displace the adsorbed heavy metal by ion exchanging process. Besides, EDTA is functioning as chelating agent, which can simultaneously coordinate to a metal ion between the six donor atoms.

Biomass has shown a greater selectivity towards lead ion based on the result of adsorption. However, the uptake level of metal ion does not reflect the desorption ability. It is because lead has a lower recovery compared with copper 
in single solution. Lead might have stronger bond with the functional group of the biomass due to its ionic size and electro negativity.

\section{Reference}

[1] Abdullah M.Z., Sites of Metal Deposition on the Biomass of Schzophyllum commune, BEng Dissertation, USM, Perak, Malaysia, 1999.

[2] Esposito, A., Pagnanelli, F., Veglio, F., pH-Related Equilibria Models for Biosorpion in Single Metal System, Chemical Engineering Science, Vol 57, Elsevier Science Ltd, 307-313, 2001.

[3] Guangyu, Y., and Viraraghavan, T., Effect of Pretreatment on the Biosorption of Heavy Metals on Mucor rouxii, Water SA, 26, 119-121, 2000.

[4] Chu, K.H., Hashim, M.A., Phang, S.M., and Samuel, V.B., Biosorption of Cadnium By Algae Biomass: Adsorption and Desorption Characteristic, Water Science and Technology, 35:115-122, 1997.

[5] Gardea-Torresdey, J.L., Gonzalez, J.H., Tiemann, K.J. and Rodriduez, O., Biosorption of Cadnium, Chronium, Lead, and Zinc By biomass of Medicago Sativa (Alfalfa), Journal of Hazardous Materials, 48: 181-190, 1996.

[6] Chu, K.H., Hashim, M.A., Phang, S.M., and Samuel, V.B., Biosorption of Cadnium By Algae Biomass: Adsorption and Desorption Characteristic, Water Science and Technology, 35:115-122, 1997.

[7] Al-Asheh S., Abdel Jabar N., and Banat F., Packed-Bed Sorption of Copper Using Animal Bones: Factorial Experimental Design, Desorption and Column Regeneration. Journal of Advance in Environment Research, 6, 3: 221-227, 1997.

[8] Waihung, L., Mui-Fong, W. and Hong, C., 2002, $<$ http://www.ct.ornl.gov/symposium/22nd/index_files/poster03.40.htm>

[9] A. Blanco, B. Sanz, M. J. Llama and J. L. Serra, 2002, $<$ http://bab.portlandpress.com/bab/027/bab0270167.htm>

[10] Sadowski, Z., Effect of Biosorption of $\mathrm{Pb}(\mathrm{II}), \mathrm{Cu}(\mathrm{II})$, and $\mathrm{Cd}(\mathrm{II})$ on the Zeta Potential and Flocculation of Nocardia Sp., Mineral Engineering, Vol 14, Elsevier Science Ltd, 547-552, 2001

[11] Laksanalamai, V and Ilangantileke, I. Comparison of Aroma Compound (2-Acetyl-1-Pyrroline) in Leaves from Pandan (Pandanus amaryllifolius) and Thai Fragrant Rice (Khao Dawk Mali-105), Cereal Chem. 70:381384, 2002.

[12] Hashim, M.A., Tan, H.N., Chu, K.H., Immobilized Marine Algal Biomass for Multiple Cycles of Copper Adsorption and Desorption. Separation and Purification Technology, 19: 39-42, 2000. 